- Communication-

\title{
Preparation of Cobalt Films by Electrodeposition at the Interface between Two Liquid Phases
}

\author{
Hiroyuki KANEKO*, Hitoshi TAIMATSU and Tsukasa TAKAHASHI \\ Received February 16, 1993 ; Accepted April 5, 1993
}

\section{Introduction}

The two-dimensional metallic deposit named as "metal leaf" grows by the cathodic reduction of a metal along the interface between an organic liquid insoluble in water and an aqueous solution of the metal ${ }^{1-3)}$. The authors found that film-like deposits, morphologically different from usual spokelike metal leaves, could be obtained under limited conditions ${ }^{4), 5}$, and recently, developed a new technique for continuousiy obtaining a very thin metallic film ${ }^{6)}$ : a zinc film with a thickness of about $1 \mu \mathrm{m}$ was grown uni-directionally along the n-butyl acetate/zinc sulfate solution interface. In the present study, the growth pattern and the morphology of cobalt films electrodeposited at the heptane/cobalt sulfate solution interface have been investigated.

\section{Experimental}

The apparatus used is shown in Fig. 1. The cell with a water-jacket was filled with an aqueous cobalt sulfate solution in the concentration range of 0.5 to $2 \mathrm{~mol} \cdot \mathrm{dm}^{-3}$, the surface of which was covered with a small amount of heptane. An aluminium foil $10 \mathrm{~mm}$ wide and $15 \mu \mathrm{m}$ thick as a cathode was floated at the interface between the aqueous solution and the heptane. A cobalt plate as an anode was positioned vertically to the cathode so that applied current flowed only to the growing front of the film. Electrodepostion of cobalt films was conducted in the temperature range of 25 to $40^{\circ} \mathrm{C}$, in the applied

Department of Materials Engineering and Applied Chemistry, Mining College, Akita University, 1-1 Tegata-Gakuencho, Akita 010, Japan

Key words: electrodeposition, cobalt, metallic film, filmy growth

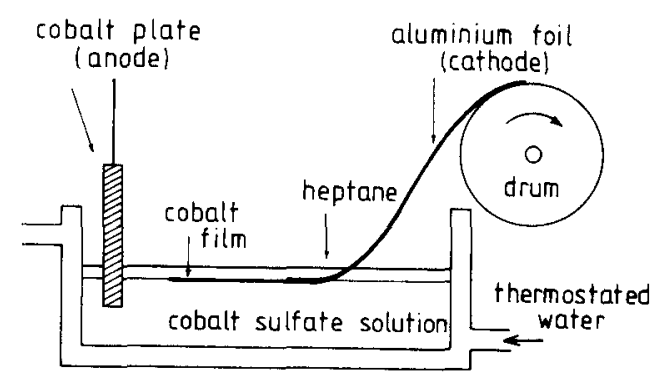

Fig. 1 Experimental set-up.

voltage range of 4 to $8 \mathrm{~V}$ or the applied current range of 100 to $200 \mathrm{~mA}$. The film growing at the interface was rolled onto the drum by a computer-controlled stepping motor so that the distance between the film and the anode was maintained at about $3 \mathrm{~mm}$.

\section{Results and Discussion}

The growth morphology of a cobalt film depended on several factors. The film growing at $100 \mathrm{~mA}$ at $30^{\circ} \mathrm{C}$ is shown in Fig. 2 . In the initial stage of the electrodeposition, the film grew circularly to the anode, and then its width became narrow. When a part of the growing front of the film happened to be submerged in the aqueous solution, the part did not grow any longer. Therefore, the condition that the film can easily be floated at the interface by the interfacial tension is necessary for the film to continue to grow uniformly. The growth rate of the film was about $8 \mathrm{~mm} \cdot \mathrm{min}^{-1}$. The current efficiency, which was calculated from the weight of the film and the quantity of electricity passed, was $100 \%$ unless very high voltage or current was applied. Assuming that the film is perfectly dense, the calculated thickness is $3 \mu \mathrm{m}$.

The organic liquid side of the film was 

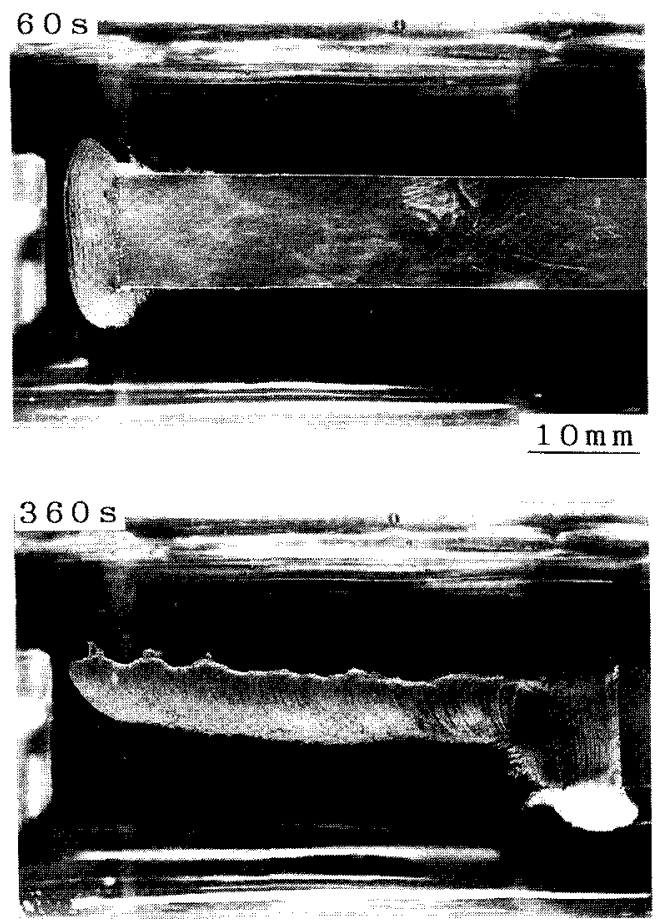

Fig. 2 Growth morphology of a cobalt film. Applied current $=100 \mathrm{~mA}$, temperature $=30^{\circ} \mathrm{C}$, $\mathrm{CoSO}_{4}$ concentration $=0.5 \mathrm{~mol} \cdot \mathrm{dm}^{-3}$

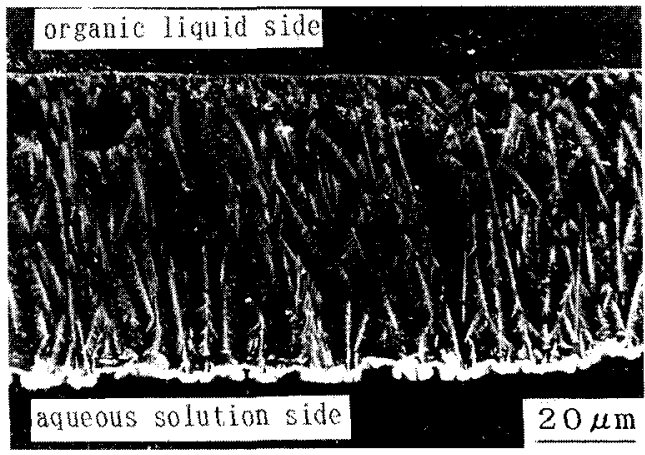

Fig. 3 Cross-sectinal view of a cobalt film.

lustrous, but its aqueous solution side was sooty. This difference of the appearance was due to the surface structure of the film. The cross-sectional view of the film is shown in Fig. 3. The film was composed of two layers. The layer facing on the organic liquid is a thin compact film with a thickness of about 1 $\mu \mathrm{m}$, and it is covered with very fine fur. The layer facing on the aqueous solution consists of less dense aggregates of spokes growing toward the aqueous solution, and accretions ride on the tips of the spokes. The thickness of the total lavers was $65 \mu \mathrm{m}$. This value is much higher than calculated one, $3 \mu \mathrm{m}$, suggesting that the layer facing to the aqueous solution side has a porosity of $97 \%$.

Two types of two-dimensional deposits, spoke-like and film-like, can be obtained by the electrodeposition at the interface between two liquid phases. It is known that the spoke-like growth is favored at high applied voltages or currents ${ }^{32}$, consistent with the prediction from the diffusion-limited aggregation model ${ }^{73}$. In the present study, too, spoke-like deposits preferentially grew at lower temperatures and at higher applied voltages or currents under the experimental conditions examined. Therefore, the electrodeposition of a film must be conducted at an applied voltage or current as low as possible and at a temperature as high as possible unless the volatilization of the organic liquid is so serious.

Cobalt films, as well as zinc films obtained in the previous study $y^{6}$, could be electrodeposited uni-directionally at the heptan/aqueous $\mathrm{CoSO}_{4}$ solution interface by choosing appropriate experimental conditions on temperature, $\mathrm{CoSO}_{4}$ concentration and applied voltage or current. This technique has an advantage of obtaining metallic films a few micrometers in thickness without using any substrates for deposition. Therefore, the technique will be expected to be widely applied for the preparation of very thin metallic films.

\section{References}

1) F. Mylius and O. Fromm, Ann. Phys. Chem, 51,593 (1894).

2) H. Freundrich and W. Novikov, Z. Electrochem., 16, 394 (1910).

3) R. Tamamushi and H. Kaneko, Electrochim. Acta, 25, 391 (1980).

4) H. Kaneko, H. Sakahara and H. Taimatsu, J. Mining and Materials Processing Inst. Jpn., 107, 542 (1991).

5) H. Sakahara, H. Kaneko and H. Taimatsu, Hyoumen Gijutsu, 43, 1059 (1992)

6) H. Kaneko, H. Taimatsu and H. Sakahara, Mater. Trans. Jpn. Inst. Metals, to be published.

7) T.A. Witten and L.M. Sander, Phys. Rev. Lett., 47, 1400 (1981). 